\title{
A Hybrid Method for Credit Risk Assessment of Bank Customers
}

\author{
Sanaz Pourdarab, Ahmad Nadali and Hamid Eslami Nosratabadi
}

\begin{abstract}
Credit risk assessment is one of the crucial issues which financial institutions particularly banks are faced and determining the effective variables is one of the critical parts in this type of studies. The purpose of this research is to present a hybrid method for evaluating credit risk of bank customers. Here, after extracting significant financial ratios from balance sheet, Kolmogorove-Smirnov test has been used to specify kind of financial ratios distribution. Then, $T$ test has been run to select meaningful variables and DEMATEL method to determine effective ones. Finally, a Fuzzy Expert system has been developed to assess credit risk according to specified effective financial ratios as the system inputs. The presented steps have been studied in an Iranian Bank as empirical study.
\end{abstract}

Index Terms- Credit Risk Assessment, MCDM, DEMATEL, Fuzzy Expert system.

\section{INTRODUCTION}

Commercial banks provide financial products and services to clients while managing a set of multi-dimensional risks associated with liquidity, capital adequacy, credit, interest and foreign exchange rates, operating and sovereign risks, etc. Banks take risks, and transform or embed such risks to provide products and services. Banks are also "profit-seeking" organizations basically formed to make money for shareholders. Management of risk and profitability are very closely related. Therefore, banks may not live without managing these risks. Among the different banking risks, credit risk has a potential "social" impact because of the number and diversity of stakeholders affected. A potential client's credit risk level is often evaluated by the bank's internal credit scoring models. Some studies have used Data Envelopment Analysis(DEA) for predicting Credit Risk [1].In the area of DEMATEL, there are previous studies around this matter including paper [2] which Combined DEMATEL technique with a MCDM model to explore portfolio selection and paper [3] which suggests a hybrid MCDM model combined with DEMATEL and ANP and paper [4] uses DEMATEL for selecting optimal management systems and paper[5] for selecting Supply chain management(SCM)

First Author, Sanaz Pourdarab is with the Department of Information Technology Management, Science and Research Branch, Islamic Azad University, Tehran, Iran (Email:Pourdarab.sanaz@yahoo.com).

Second Author, Ahmad Nadali is with the Department of Information Technology Management, Science and Research Branch, Islamic Azad University, Tehran, Iran (Email:Nadali.ahmad@gmail.com).

Third Author, Hamid Eslami Nosratabadi is with the Department of Information Technology Management, Science and Research Branch, Islamic Azad University, Tehran, Iran (Corresponding author's email is Hamideslami.na@gmail.com). suppliers and paper [6] for producing effective evaluation of e-learning programs and paper [7] for a job-seeking service. Regarding the studies about Credit Risk, Recent studies have considered new non-parametric methods such as mathematical programming, classification trees, neural networks[8], [9], [10], [11] and support vector machines. As [12] is suggesting that highly complex or non-linear models are not expected to have a considerable predicting ability compared to simpler models. Paper [13] explores the performance of credit scoring using ANN and multivariate adaptive regression splines (MARS). Paper [14] neural network to evaluate credit risk.

Credit scoring has both financial and non-financial aspects. The scope of the current paper, however, is limited to the evaluation of a bank client's financial performance. In this paper, a Fuzzy Expert system has been used to evaluate the credit risk of Bank Legal customers. Studying the financial cases of companies as the bank customers is noticeable for bank experts as the proper solution to identify the credit risk level. Here, the aim is analyzing the customers' credit risks based on the experts' analysis obtained from the financial ratios. The ratios have been extracted from financial Balance sheets. So the knowledge which helps the bank experts to make connection between the customers' credit risk level and financial situations can be acquired in form of rules. In this study, a Fuzzy Expert system has been designed in which the case of customers' financial ratios will be considered as the Inputs and the level of predicted credit risk as the output. Regarding to the fact that all financial ratios for companies are not enough important for the experts to make decision, the financial ratios which are more effective on determination of credit risk of companies, have been filtered and these financial filtered ratios have been considered in decision making. The rest of this paper is structured as follows: In the next section, literature review is presented. In section 3 research methodology is described. Section 4 will focus on the proposed model and its use in the case of Saman Iranian Bank. In the final section, some conclusions are drawn from the study.

\section{LITERATURE REVIEW}

\section{A. Credit Risk Assessment}

Credit scoring is a technique that helps some organizations, such as commercial banks and credit card companies; determine whether or not to grant credit to consumers, on the basis of a set of predefined criteria [15]. Credit scoring tasks can be divided into two distinct types: The first type is application scoring, where the task is to classify credit 
applicants into "good" and "bad" risk groups. The data used for modeling generally consists of financial information and demographic information about the loan applicant. In contrast, the second type of tasks deals with existing customers and along with other information, payment history information is also used here. This is distinguished from the first type because this takes into account the customer's payment pattern on the loan and the task is called behavioral scoring. Recently, under BASEL II committee recommendations [13], it is increasingly becoming almost a regulatory requirement for the banks to use sophisticated credit scoring models for enhancing the efficiency of capital allocation. Usually, a credit score is a number that quantifies the creditworthiness of a person, based on a quantitative analysis of credit history and other criteria; it describes the extent to which the borrower is likely to pay his or her bills/debt. A credit score is primarily based on credit reports and information received from some major credit reporting agencies. Using credit scores, banks and credit card companies evaluate the potential risk involved in lending money, in order to minimize bad debts. Lenders can also use credit scores to determine who qualifies for what amount loan and at what interest rate. The generic approach of credit scoring is to apply a quantitative method on some data of previous customers - both faithful and delinquent customers in order to find a relationship between the credit scores and a set of evaluation criteria. One important ingredient to accomplish this goal is to seek a good model so as to evaluate new applicants or existing customers as good or bad. In credit scoring, a generic process consists of two procedures: (1) applying a quantitative technique on similar data of previous customers - both faithful and delinquent customers - to uncover a relationship between the credit scores and a set of criteria; (2) utilizing the discovered relationship and new applicants' credit data to score new applicants and to evaluate new applicants as good or bad applicants [16].

\section{B. DEMATEL Method}

The DEMATEL method is based upon graph theory, enabling us to plan and solve problems visually, so that we may divide multiple criteria into a cause-and-effect group, to better understand causal relationships to plot a network relationship map. Directed graphs (also called digraphs) will demonstrate the directed relationships of sub-systems The DEMATEL method can be summarized in the following steps: Step 1: Find the average matrix. Suppose we have $\mathrm{H}$ experts and $n$ criteria to consider. Each expert is asked to indicate the degree which represents he or she believes a criterion $\mathrm{i}$ affects criterion $\mathrm{j}$. These pairwise comparisons are denoted by aij and are given an integer score ranging from 0 , $1,2,3$, and 4, representing 'No influence (0),' 'Low influence (1),' 'Medium influence (2),' 'High influence (3),' and 'Very high influence (4),' respectively. We can then compute the $\mathrm{n} \times \mathrm{n}$ average matrix $\mathrm{A}$ for all expert opinions by averaging the H experts' scores as follows:

$\left[a_{i j j}\right] \mathrm{n} \times \mathrm{n}=1 / H \quad \sum_{k=1}^{H}\left[x_{i j}^{k}\right]_{n \times n}$

The average matrix $A=[a i j] n \times n$ is also called the initial direct relation matrix. A shows the initial direct effects that a criterion exerts on and receives from other criteria. Fig. 1 below is an example of such a network influence map. Each letter represents a criterion in the system. An arrow from $\mathrm{c}$ to $\mathrm{d}$ shows the effect that $\mathrm{c}$ has on $\mathrm{d}$, and the strength of its effect is 4. DEMATEL can convert the structural relations among the criteria of a system into an intelligible map of the system.

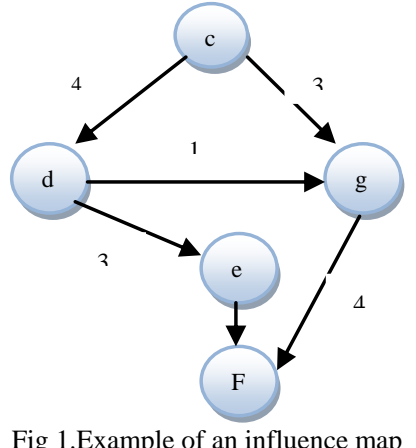

Step 2: Calculate the normalized initial direct-relation matrix. The normalized initial direct-relation matrix $\mathrm{D}$ is obtained by normalizing the average matrix $\mathrm{A}$ in the following way:

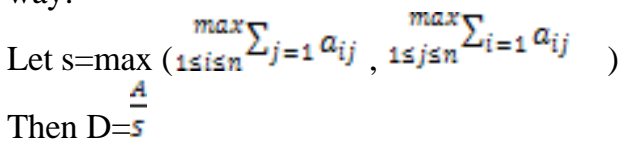

Since the sum of each row $i$ of matrix A represents the total direct effects that criterion $\mathrm{i}$ gives to the other criteria, represents the total direct effects of the criterion with the most direct effects on others. Likewise, since the sum of each column $\mathrm{j}$ of matrix $\mathrm{A}$ represents the total direct effects received to other criteria by criterion $i$, represents the total direct effects that the criterion $j$ receives the most direct effects from other criteria. Step 3: Compute the total relation matrix. The total relation matrix $\mathrm{T}$ is an $\mathrm{n} \times \mathrm{n}$ matrix and is defined as follow:

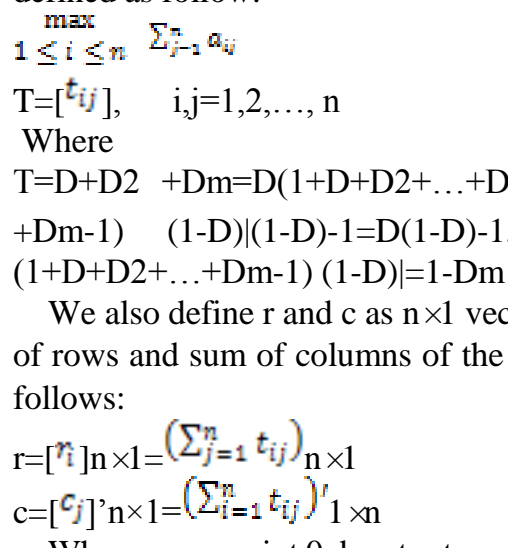

$\mathrm{T}=\mathrm{D}+\mathrm{D} 2+\mathrm{Dm}=\mathrm{D}(1+\mathrm{D}+\mathrm{D} 2+\ldots+\mathrm{D} \quad \mathrm{m}-1)=\mathrm{D} \mid(1+\mathrm{D}+\mathrm{D} 2+.$.

$+\mathrm{Dm}-1) \quad(1-\mathrm{D}) \mid(1-\mathrm{D})-1=\mathrm{D}(1-\mathrm{D})-1, \quad$ as $\quad \mathrm{m} \rightarrow \infty$ and

We also define $r$ and $c$ as $n \times 1$ vectors representing the sum of columns of the total relation matrix $\mathrm{T}$ as

Where superscript 0 denotes transpose. Thus when $\mathrm{j}=\mathrm{i}$, the sum $(\mathrm{ri}+\mathrm{ci})$ gives us an index representing the total effects both given and received by criterion $\mathrm{i}$. In other words, $(\mathrm{ri}+\mathrm{ci})$ shows the degree of importance (total sum of effects given and received) that criterion i plays in the system. In addition, the difference (ri - ci) shows the net effect that criterion I contributes to the system. When (ri - ci) is positive, criterion $\mathrm{i}$ is a net causer, and when (ri - ci) is negative, criterion $\mathrm{i}$ is a net receiver. Step 4: Set a threshold value and obtain the network relationship map (NRM). In order to explain the structural relation among the criteria and keep the complexity of the system to a manageable level at the same time, it is necessary to set a threshold value $\mathrm{p}$ to filter out some negligible effects in matrix T. Only some criteria, whose effect in matrix $\mathrm{T}$ is greater than the threshold value, should be chosen and shown 
in a network relationship map (NRM) for influence. After the threshold value is decided, the final influence result of criteria can be shown in a NRM. [17].

\section{Fuzzy Expert System}

Fuzzy Expert System is simply an expert system that uses a collection of fuzzy membership functions and rules, instead of Boolean logic, to reason about data. Fuzzy Inference System (FIS) incorporates fuzzy inference and rule-based expert systems. There are different types of fuzzy systems are introduced. Mamdani fuzzy systems and TSK fuzzy systems are two types of fuzzy systems commonly used in literature that has different ways of knowledge representation.TSK (Takagi-Sugeno-Kang) fuzzy system was proposed in an effort to develop a systematic approach to generate fuzzy rules from a given input-output data set. Rules in this fuzzy system are like:

If $\mathrm{x} 1$ is $\mathrm{A} 1 \mathrm{AND} / \mathrm{OR} \mathrm{x} 2$ is $\mathrm{A} 2$ Then $\mathrm{y}=\mathrm{f}(\mathrm{x} 1, \mathrm{x} 2)$

Where A1 and A2 are fuzzy sets and y is a (usually linear) function of crisp variables. In order to perform inference operations, the output of each rule have to be weighted. For example regarding the $\mathrm{jth}$ rule

$\mathrm{Wj}=\mathrm{AND}$ method $\left(\mu_{A j}\left(\mathrm{x}_{1}\right), \mu_{B j}\left(\mathrm{X}_{2}\right)\right)$

$\mathrm{Rj}$ : If $\mathrm{x} 1$ is $\mathrm{Aj} A N D \mathrm{x} 2$ is $\mathrm{Bj}$ Then $\mathrm{yj}=\mathrm{fj}(\mathrm{x} 1, \mathrm{x} 2)$

$\mu_{A j}($.$) and \mu_{B j}($.

The weight $\mathrm{wj}$ is computed as where are membership functions of $\mathrm{Aj}$ and $\mathrm{Bj}$, respectively, and the ANDmethod is the operation defined by the AND operator which is usually the " $\min$ " operation. Then the final output of the system will be obtained by final output (4)

Final output $=\sum_{j} w_{j} y_{j} / \Sigma_{j} w_{j}$

Mamdani fuzzy system was proposed as the first attempt to control a steam engine and boiler combination by a set of linguistic control rules obtained from experienced human operators. Rules in Mamdani fuzzy systems are like these: If $\mathrm{x} 1$ is $\mathrm{A} 1 \mathrm{AND} / \mathrm{OR} \mathrm{x} 2$ is $\mathrm{A} 2$ Then $\mathrm{y}$ is $\mathrm{B} 1$

Where A1, A2 and B1 are fuzzy sets. The fuzzy set acquired from aggregation of rules' results will be defuzzified using defuzzification methods like centroid (center of gravity), max membership, mean-max, and weighted average. The centroid method is very popular, in which the "center of mass" of the result provides the crisp value. In this method, the defuzzified value of fuzzy set A, d (A), is calculated by the formula (5)

$\mathrm{d}(\mathrm{A})=\int_{A} x \cdot \mu_{A}(x) d x / \int_{A} \mu_{A}(x) d x$

where is the membership function of fuzzy set A .Regarding our problem in which various possible conditions of parameters are stated in form of fuzzy sets, the Mamdani fuzzy systems will be utilized due to the fact that the fuzzy rules representing the expert knowledge in Mamdani fuzzy systems, take advantage of fuzzy sets in their consequences, while in TSK fuzzy systems, the consequences are expressed in form of a crisp function [18].

\section{ReSEARCH Methodology}

The major steps followed in the practical study of this research, have been implemented in Saman bank. Here, the steps briefly have been explained as follows:

Step1.Extracting significant financial ratios for credit risk assessment of bank customers by balance sheet

Step2.Checking financial ratios distribution to make sure the rations are normal using Kolmogorove-Smirnov test

Step3.Selecting meaningful variables according to specified distribution type

Step4.Determining the effective financial ratios based on DEMATEL method

Step5.Designing Fuzzy Expert System for credit risk assessment

In this regard, for designing Fuzzy Expert System, the following steps have been done:

Step5.1. Selecting the Input and output variables with the use of previous studies. Besides, meaningful linguistic states along with appropriate fuzzy sets for each variable should be selected.

Step5.2. Determining the membership functions for the variables.

Step5.3. Specifying rules to make clear the relations between Inputs and outputs.

Step5.4. Developing the Fuzzy Expert System via FIS Tool in MATLAB Software.

Step5.5. Credit risk assessment for bank customers based on the designed system.

The flowchart of the research is shown in Fig 2. In next section, the results of each step have been presented elaborately.

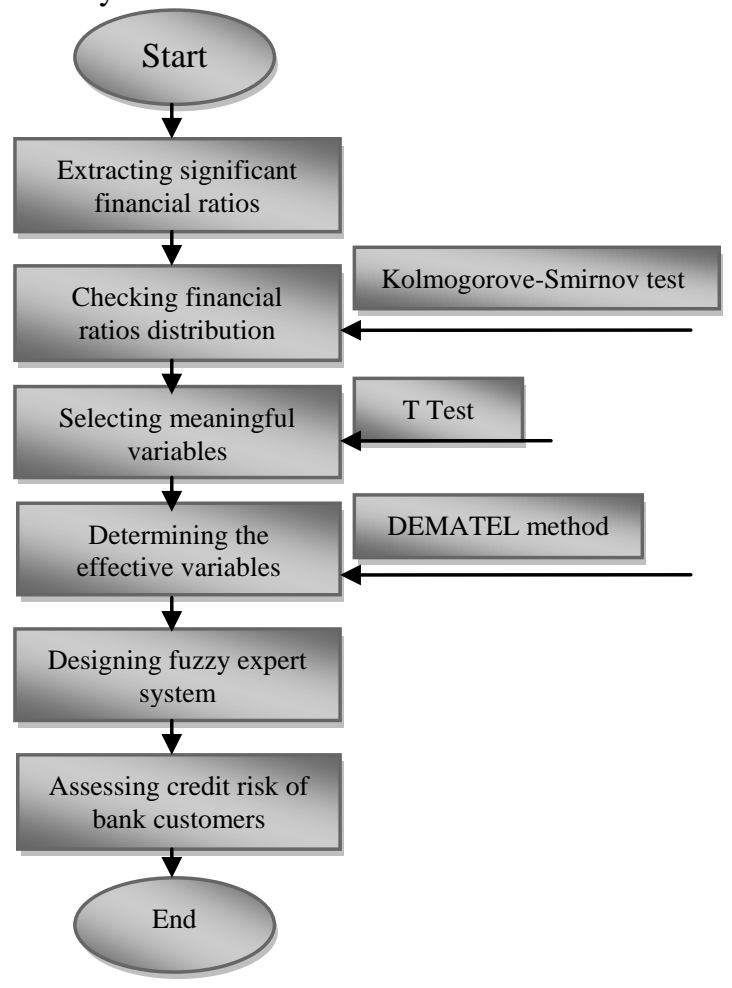

Fig.2. Flow chart of hybrid method for credit risk assessment 
TABLE1. KOLMOGOROVE-SMIRNOV TEST RESULTS

\begin{tabular}{|c|c|c|c|c|c|c|c|c|}
\hline \multirow[t]{2}{*}{ Criteria } & \multirow[t]{2}{*}{$N$} & \multicolumn{2}{|c|}{ Normal Parameters } & \multicolumn{3}{|c|}{ Most Extreme Differences } & \multirow{2}{*}{$\begin{array}{l}\text { Kolmogorov-S } \\
\text { mirnov } Z\end{array}$} & \multirow{2}{*}{$\begin{array}{c}\text { Asymp. Sig. } \\
\text { (2-tailed) }\end{array}$} \\
\hline & & Mean & Std. Deviation & Absolute & Positive & Negative & & \\
\hline $\mathrm{C} 1$ & 18 & 4.50 & 0.51 & 0.33 & 0.33 & -0.33 & 1.42 & 0.14 \\
\hline $\mathrm{C} 2$ & 18 & 3.39 & 0.70 & 0.31 & 0.21 & -0.31 & 1.31 & 0.16 \\
\hline $\mathrm{C} 4$ & 18 & 3.22 & 0.73 & 0.24 & 0.23 & -0.24 & 1.04 & 0.23 \\
\hline $\mathrm{C} 5$ & 18 & 3.50 & 0.92 & 0.26 & 0.18 & -0.26 & 1.11 & 0.17 \\
\hline $\mathrm{C} 8$ & 18 & 2.78 & 0.65 & 0.30 & 0.25 & -0.30 & 1.28 & 0.18 \\
\hline C9 & 18 & 3.72 & 0.96 & 0.23 & 0.16 & -0.23 & 0.96 & 0.32 \\
\hline $\mathrm{C} 10$ & 18 & 3.50 & 0.51 & 0.33 & 0.33 & -0.33 & 1.42 & 0.14 \\
\hline C11 & 18 & 3.83 & 0.38 & 0.50 & 0.33 & -0.50 & 2.13 & 0.20 \\
\hline $\mathrm{C} 12$ & 18 & 4.61 & 0.50 & 0.39 & 0.28 & -0.39 & 1.66 & 0.11 \\
\hline
\end{tabular}

\section{RESULTS AND DISCUSSION}

Evaluating credit risk for bank customers is based on the financial analysis. In first step, financial variables which are important for bank experts to assess the level of legal customers' risk, have been selected. The followings are the extracted financial ratios from the balance sheet that have been reviewed by bank experts, for assessing the loan applicants: Current Ratio(C1), Quick Ratio (C2), Asset Turnover(C3), Cash Ratio(C4), Working Capital Turnover(C5), Average Collection Period(C6), Inventory Period(C7), Debt Coverage Ratio(C8), Debt Ratio(C9), Current Debt to Net worth(C10), Gross Profit Ratio(C11), Return on Equity(C12), Return on Assets(C13), Payout Ratio(C14), Return On Sales(C15) and Debt to equity ratio(C16).

Since 16 variables between financial ratios for making decision to rank credit customers have been extracted from their financial balance sheet and some of them could be meaningless, they have not been involved in decision making process and have been removed in next modelling. So the opinions from the 18 bank financial experts have been obtained by Likert scale questionnaire. To select the useful solution, It is necessary to specify statistical status of sample distribution. For this purpose, the Kolmogorove-Smirnov test has been used.

The Hypothesis tests are as follows:

$\mathrm{H}_{0}$ : The Financial ratio is normal.

$\mathrm{H}_{1}$ : The Financial ratio is not normal.

The obtained results of SPSS software is shown in Table 1.

According to the Kolmogorove-Smirnov test for Sig higher than 5 percent, The $\mathrm{H}_{0}$ Hypothesis will not be rejected and It will be shown that financial ratio is normal. Here, we are allowed to use parametric statistics. Therefore, $\mathrm{T}$ test will be used to evaluate meaningful variables. According to obtained results, 12 variables from 16 ones are Sig higher than 5 percent and they are meaningful apart from C4, C7, C12 and C16. Table 2 shows the test results for 16 variables. Therefore, 12 Variables considered here, have been used in next steps modelling,

The main variables that are most effective in decision making process and the experts' judgment for determining customers' credit risk, have been chosen and prioritized via
DEMATEL technique. To evaluate the important degree for the 12 financial ratios with the use of experts' opinions, DEMATEL steps have been run. Table 3 shows the factor scores and related values for cause and effect groups as the sum of given and received influences on criteria. The Criteria Total Relation Matrix has been extracted from this table.

\begin{tabular}{|c|c|c|c|c|c|c|}
\hline \multicolumn{7}{|c|}{ Test Value $=3$} \\
\hline & \multirow[t]{2}{*}{$\mathrm{t}$} & \multirow[t]{2}{*}{ df } & \multirow[t]{2}{*}{$\begin{array}{l}\text { Sig. } \\
\text { (2-taile } \\
\text { d) }\end{array}$} & \multirow[t]{2}{*}{$\begin{array}{c}\text { Mean } \\
\text { Difference }\end{array}$} & \multicolumn{2}{|c|}{$\begin{array}{l}\text { 95\% Confidence } \\
\text { Interval of the } \\
\text { Difference }\end{array}$} \\
\hline & & & & & Lower & Upper \\
\hline $\mathrm{C} 1$ & $\begin{array}{c}12.36 \\
9\end{array}$ & 17 & .000 & 1.50000 & 1.2441 & 1.7559 \\
\hline $\mathrm{C} 2$ & 2.364 & 17 & .030 & .38889 & .0419 & .7359 \\
\hline C3 & $\begin{array}{c}12.90 \\
7\end{array}$ & 17 & .000 & 1.55556 & 1.3013 & 1.8098 \\
\hline $\mathrm{C} 4$ & 1.288 & 17 & .215 & .22222 & -.1418 & .5863 \\
\hline C5 & 2.297 & 17 & .035 & .50000 & .0407 & .9593 \\
\hline C6 & 4.123 & 17 & .001 & .50000 & .2441 & .7559 \\
\hline $\mathrm{C} 7$ & .809 & 17 & .430 & .11111 & -.1788 & .4010 \\
\hline $\mathrm{C} 8$ & 3.198 & 17 & .005 & .72222 & .2457 & 1.1988 \\
\hline C9 & 4.123 & 17 & .001 & .50000 & .2441 & .7559 \\
\hline $\begin{array}{c}\mathrm{C} 1 \\
0\end{array}$ & 9.220 & 17 & .000 & .83333 & .6426 & 1.0240 \\
\hline $\begin{array}{c}\mathrm{C} 1 \\
1\end{array}$ & $\begin{array}{c}13.62 \\
6\end{array}$ & 17 & .000 & 1.61111 & 1.3617 & 1.8606 \\
\hline $\begin{array}{c}\mathrm{C} 1 \\
2\end{array}$ & -.325 & 17 & .749 & -.05556 & -.4163 & .3052 \\
\hline $\begin{array}{c}\mathrm{C} 1 \\
3\end{array}$ & 4.973 & 17 & .000 & .88889 & .5117 & 1.2660 \\
\hline $\begin{array}{c}\mathrm{C} 1 \\
4\end{array}$ & 3.289 & 17 & .004 & .38889 & .1394 & .6383 \\
\hline $\begin{array}{c}\mathrm{C} 1 \\
5\end{array}$ & 3.198 & 17 & .005 & .72222 & .2457 & 1.1988 \\
\hline $\begin{array}{c}\mathrm{C} 1 \\
6 \\
\end{array}$ & -1.458 & 17 & .163 & -.22222 & -.5438 & .0994 \\
\hline
\end{tabular}

\begin{tabular}{c|cccc}
\multicolumn{5}{c}{ TABLE 3. THE SUM OF INFLUENCES GIVEN AND RECEIVED ON CRITERIA } \\
\hline $\begin{array}{l}\text { Criteri } \\
a\end{array}$ & $R$ & $J$ & $R+J$ & $R-J$ \\
\hline C1 & 3.1372 & 1.9415 & 5.0787 & 1.1957 \\
C2 & 3.3106 & 2.1526 & 5.4632 & 1.158 \\
C3 & 1.9003 & 3.064 & 4.9643 & -1.1637 \\
C5 & 2.2439 & 2.8586 & 5.1025 & -0.6147 \\
C6 & 2.7273 & 2.1389 & 4.8662 & 0.5884 \\
C8 & 2.4636 & 2.9979 & 5.4615 & -0.5343 \\
C9 & 2.7695 & 1.7077 & 4.4772 & 1.0618 \\
C10 & 2.1161 & 2.689 & 4.8051 & -0.5729 \\
C11 & 2.2176 & 2.4201 & 4.6377 & -0.2025 \\
C13 & 1.6539 & 2.9217 & 4.5756 & -1.2678 \\
C14 & 2.3669 & 2.495 & 4.8619 & -0.1281 \\
C15 & 2.4525 & 1.6464 & 4.0989 & 0.8061 \\
\hline
\end{tabular}


financial ratios have been selected as the most effective financial variables.

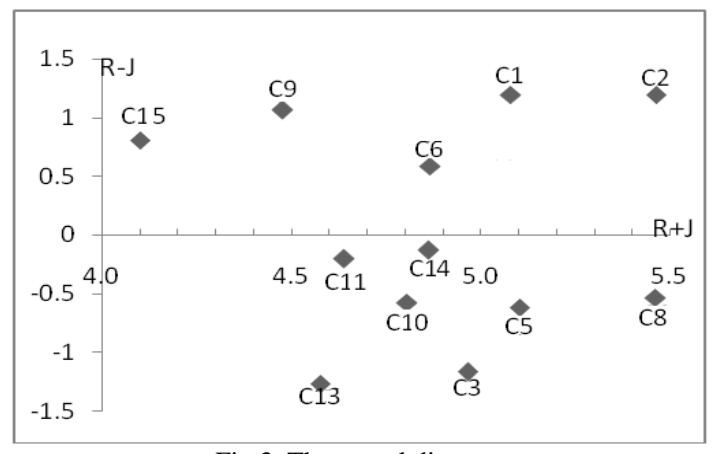

Fig 3. The causal diagram

In the next step, the filtered financial ratios from the last step have been considered as the most important criteria in decision making of bank experts to identify the credit risk of customers. According to these financial ratios as inputs (Table 4) and Credit Risk Degree of Customer as output (Table 5), the experts opinions in the form of rules have been obtained (Table 6).Then, a Mamdani's Fuzzy Expert system has been designed with the financial ratios as the system Inputs and customers credit risk degree as the output.

TABLE 4. THE INPUTS OF FUZZY EXPERT SYSTEM

\begin{tabular}{|c|c|c|c|c|}
\hline$\underset{\mathrm{n}}{\mathrm{Sig}}$ & Inputs & Interval & $\begin{array}{c}\text { Type of } \\
\text { membershi } \\
\text { p function }\end{array}$ & Linguistic terms \\
\hline $\mathrm{CR}$ & Current Ratio & {$\left[\begin{array}{ll}0 & 2\end{array}\right]$} & Gbell & $\begin{array}{c}\text { Low }(\mathrm{L}) \operatorname{Medium}(\mathrm{M}) \\
\operatorname{High}(\mathrm{H})\end{array}$ \\
\hline DR & Debit Ratio & {$\left[\begin{array}{ll}0 & 1\end{array}\right]$} & Gbell & $\begin{array}{c}\text { Low }(\mathrm{L}) \operatorname{Medium}(\mathrm{M}) \\
\operatorname{High}(\mathrm{H})\end{array}$ \\
\hline $\begin{array}{c}\text { RO } \\
\text { S }\end{array}$ & Return On Sales & {$\left[\begin{array}{ll}0 & 3\end{array}\right]$} & Gbell & $\begin{array}{c}\text { Low }(\mathrm{L}) \operatorname{Medium}(\mathrm{M}) \\
\operatorname{High}(\mathrm{H})\end{array}$ \\
\hline $\begin{array}{c}\mathrm{AC} \\
\mathrm{P}\end{array}$ & $\begin{array}{l}\text { Average } \\
\text { Collection } \\
\text { Period }\end{array}$ & {$\left[\begin{array}{ll}0 & 300\end{array}\right]$} & Gbell & $\begin{array}{c}\text { Low }(\mathrm{L}) \operatorname{Medium}(\mathrm{M}) \\
\operatorname{High}(\mathrm{H})\end{array}$ \\
\hline QR & Quick Ratio & {$\left[\begin{array}{ll}0 & 1\end{array}\right]$} & Gbell & $\begin{array}{c}\text { Low }(\mathrm{L}) \operatorname{Medium}(\mathrm{M}) \\
\operatorname{High}(\mathrm{H})\end{array}$ \\
\hline
\end{tabular}

TABLE 5. THE OUTPUT OF FUZZY EXPERT SYSTEM

\begin{tabular}{clrcc}
\hline Sign & Inputs & $\begin{array}{r}\text { Interva } \\
\mathbf{l}\end{array}$ & $\begin{array}{c}\text { Type of } \\
\text { membershi } \\
\text { p function }\end{array}$ & $\begin{array}{c}\text { Linguistic } \\
\text { terms }\end{array}$ \\
\hline $\begin{array}{c}\text { CRD } \\
\text { C }\end{array}$ & $\begin{array}{c}\text { Credit Risk } \\
\text { Degree of } \\
\text { Customer }\end{array}$ & {$\left[\begin{array}{ll}0 & 1\end{array}\right]$} & Gaussian1 & $\begin{array}{c}\text { Low(L) } \\
\text { High(H) }\end{array}$ \\
\hline
\end{tabular}

TABLE 6.THE RULES FOR DESIGNING FUZZY EXPERT SYSTEM

\begin{tabular}{c|cccccc}
\hline & $C R$ & $D R$ & $R O S$ & $A C P$ & $Q R$ & $C R D C$ \\
\hline 1 & $\mathrm{H}$ & $\mathrm{M}$ & $\mathrm{M}$ & $\mathrm{H}$ & $\mathrm{L}$ & $\mathrm{H}$ \\
2 & $\mathrm{M}$ & $\mathrm{H}$ & $\mathrm{H}$ & $\mathrm{L}$ & $\mathrm{M}$ & $\mathrm{L}$ \\
3 & $\mathrm{H}$ & $\mathrm{L}$ & $\mathrm{M}$ & $\mathrm{H}$ & $\mathrm{H}$ & $\mathrm{M}$ \\
4 & $\mathrm{M}$ & $\mathrm{H}$ & $\mathrm{H}$ & $\mathrm{M}$ & $\mathrm{M}$ & $\mathrm{H}$ \\
5 & $\mathrm{~L}$ & $\mathrm{H}$ & $\mathrm{M}$ & $\mathrm{L}$ & $\mathrm{M}$ & $\mathrm{H}$ \\
6 & $\mathrm{~L}$ & $\mathrm{~L}$ & $\mathrm{H}$ & $\mathrm{H}$ & $\mathrm{L}$ & $\mathrm{L}$ \\
7 & $\mathrm{H}$ & $\mathrm{M}$ & $\mathrm{L}$ & $\mathrm{M}$ & $\mathrm{M}$ & $\mathrm{M}$ \\
8 & $\mathrm{M}$ & $\mathrm{L}$ & $\mathrm{H}$ & $\mathrm{L}$ & $\mathrm{H}$ & $\mathrm{L}$ \\
9 & $\mathrm{H}$ & $\mathrm{H}$ & $\mathrm{L}$ & $\mathrm{M}$ & $\mathrm{M}$ & $\mathrm{M}$ \\
10 & $\mathrm{M}$ & $\mathrm{H}$ & $\mathrm{M}$ & $\mathrm{H}$ & $\mathrm{L}$ & $\mathrm{H}$ \\
\hline
\end{tabular}

With the use of MATLAB software, according to experts' opinions, for the Input and output variables, the suitable membership functions have been defined(Fig 4-9).Finally, Fuzzy Expert System has been designed based on the obtained rules from the bank experts (Appendix 1).

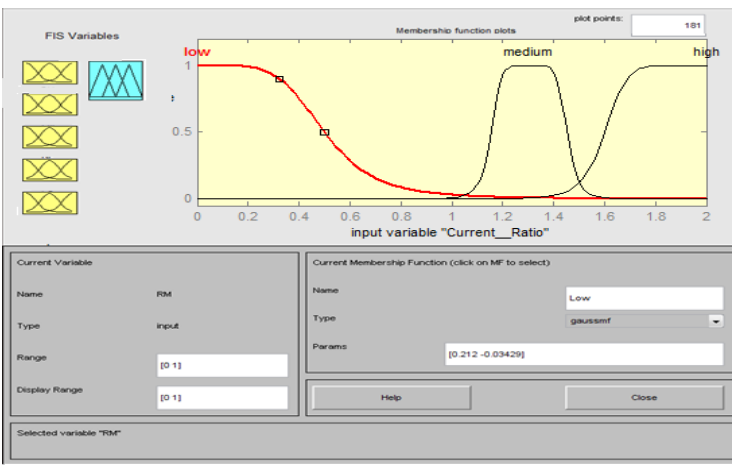

Fig 4. Three Gbell Membership functions for Current Ratio

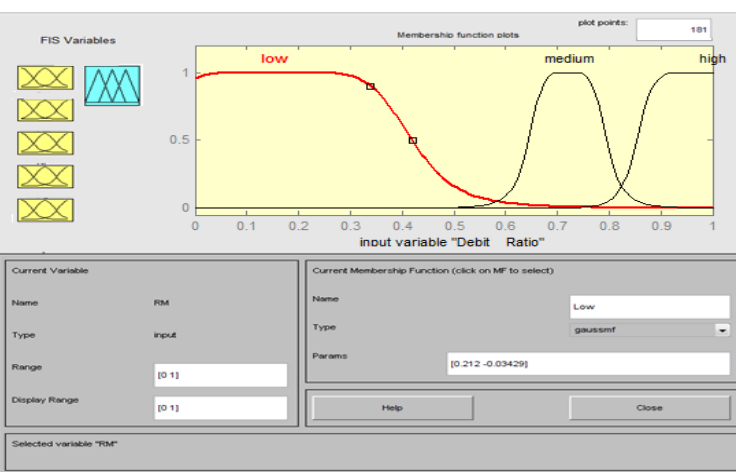

Fig 5. Three Gbell Membership function for Debt Ratio

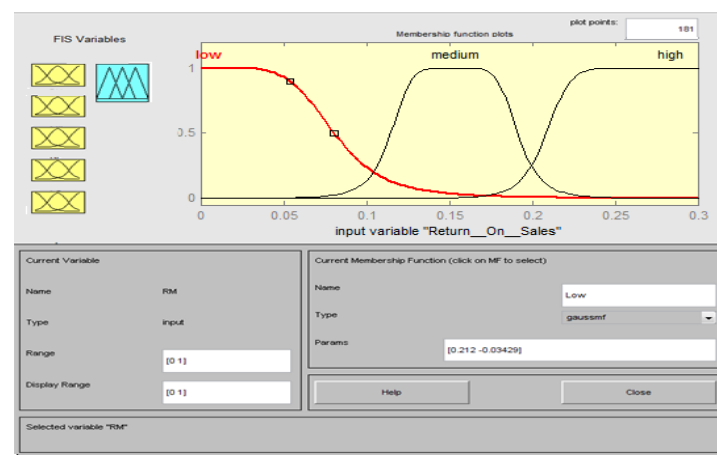

Fig 6. Three Gbell Membership functions for Return on Sales

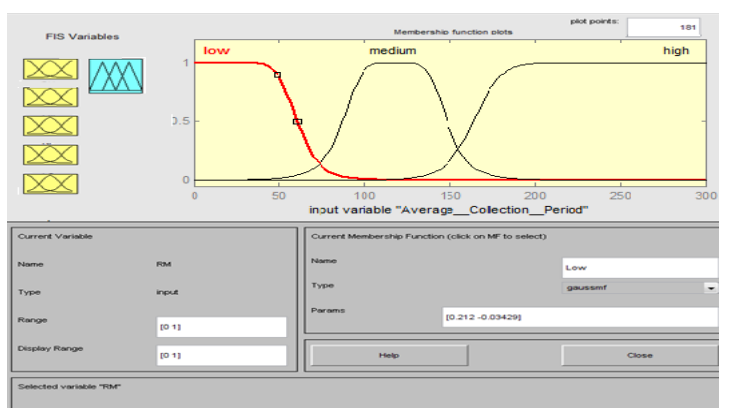

Fig 7. Three Gbell Membership functions for Average Collection Period

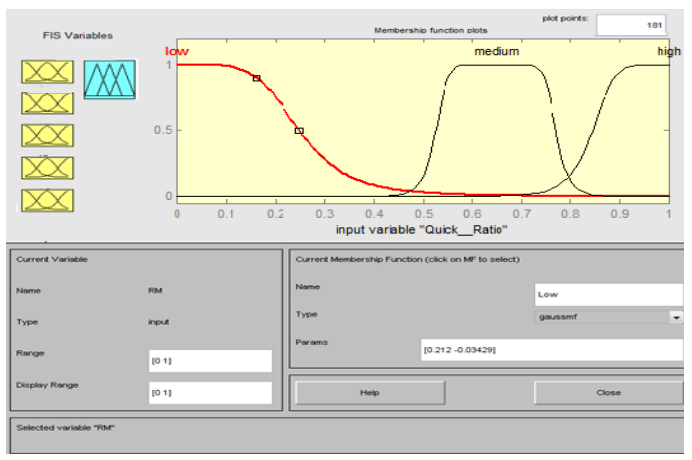

Fig 8. Three Gbell Membership functions for Quick Ratio 


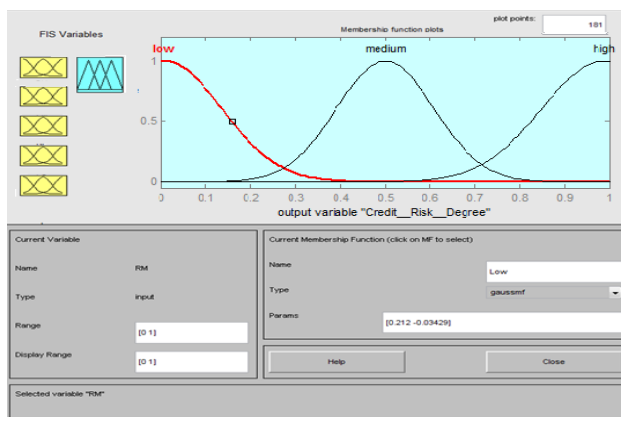

Fig 9. Three Gaussian Membership functions for Credit Risk Degree

This system can predict the level of customers credit risk by obtaining the financial ratios values. An instance of the system output is as follows (Fig10):

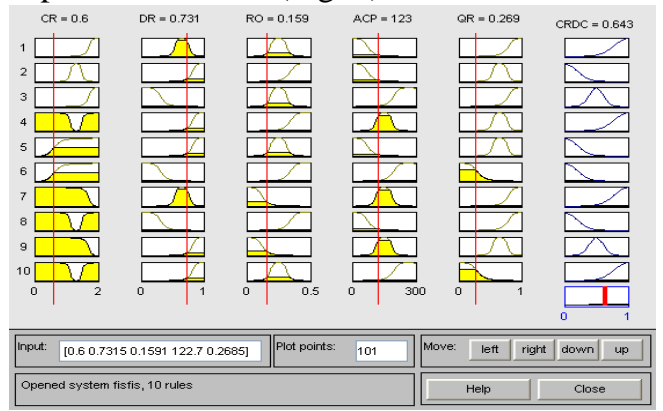

Fig 10. Assessed Credit Risk of a bank customer by designed fuzzy expert system

\section{Current Ratio $=0.6 \quad$ Debt Ratio $=0.731$ \\ Return On Sales Average Collection Period $=123$ $=0.159$ \\ Quick Ratio $=0.269 \quad$ Credit Risk Degree $=0.643$}

According to the Inputs, the considered customer credit risk degree is 0.643 out of 1 .

\section{CONCLUSION}

In this paper, a hybrid method has been presented to assess bank customers credit risk. According to this method and the proper financial ratios which are effective on the experts decision making process and the acquired rules via bank experts, a Mamdani's Fuzzy Expert system has been developed which predicts the bank Customers Credit Risk. The presented approach in this survey, can demonstrate a good solution to help bank owners and credit institutes to make them able to identify the major variables in credit assessment. The designed system is able to help the banking systems to identify the level of credit risks for their customers according to their financial status and It is a critical issue for banks. Finally, Comparison of results of the presented hybrid model with other models used in credit assessment could be studied in future research.

\section{APPENDIX}

Here, some useful MATLAB commands to work with the proposed fuzzy inference system (FIS) which is based on Mamdani are presented:

$>>$ fis $=$ readfis ('CreditRiskAssesment')

fis $=$

name: 'CreditRiskAssesment'

type: 'mamdani'

andMethod: 'min'
orMethod: 'max'

defuzzsMethod: 'centroid'

impMethod: 'min'

aggMethod:'max'

input: [ $1 * 5$ struct]

output: [1*1 struct]

rule: $[1 * 10$ struct]

\section{AKNOWLEDGEMENT}

Here, we appreciate from the Financial Experts of Saman Iranian bank to share their Knowledge with us as the researchers.

\section{REFERENCES}

[1] A.B.Emela, M.Oralb, A.Reismanb, R.Yolalan,"A credit scoring approach for the commercial banking sector," Socio-Economic Planning Sciences, 2003, 37, 103-123.

[2] W.R.J.Ho, C.L.Tsai, G.H.Tzeng, S.K.Fang,"Combined DEMATEL technique with a novel MCDM model for exploring portfolio selection based on CAPM," Expert Systems with Applications, 2011, 38, 16-25.

[3] Y.P.Ou Yang, H.M. Shieh, J.D. Leu, G.H.Tzeng,"A novel hybrid MCDM model combined with DEMATEL and ANP with applications," International Journal of Operations Research,2008, 5(3), 160-168.

[4] W.H.Tsai, W.C.Chou,"Selecting management systems for sustainable development in SMEs:A novel hybrid model based on DEMATEL, ANP, and ZOGP," Expert Systems with Applications, 2009, 36, 1444-1458.

[5] B.Chang, C.W.Chang, C.H.Wu,"Fuzzy DEMATEL method for developing supplier selection criteria," Expert Systems with Applications, 2011, 38, 1850-1858.

[6] G.H.Tzeng, C.H.Chiang, C.W.Li," Evaluating intertwined effects in e-learning programs: A novel hybrid MCDM model based on factor analysis and DEMATEL," Expert Systems with Applications, 2007, 32, 1028-1044.

[7] H.H.Wua, H.K.Chen , J.I.Shieh," Evaluating performance criteria of Employment Service Outreach Program personnel by DEMATEL method," Expert Systems with Applications, 2010, 37, 5219-5223.

[8] H.Abdou, J.Pointon, A.Elmasry,"Neural nets versus conventional techniques in credit scoring in Egyptian banking," Expert Systems and Applications, 2008, 35(3), 1275-1292.

[9] E.Angelini, G.D.Tollo, A.Roli,"A neural network approach for credit risk evaluation," The Quarterly Review of Economics and Finance, 2008, 48(4), 733-755.

[10] I.C.Yeh, C.H.Lien," The comparisons of data mining techniques for the predictive accuracy of probability of default of credit card clients," Expert Systems with Applications, 2008, in press, doi:10.1016/j.eswa.2007.12.020.

[11] L.Yu, S.Wang, K.K.Lai," Credit risk assessment with a multistage neural network ensemble learning approach," Expert Systems with Applications, 2008, 34(2), 1434-1444.

[12] B.Baesens, T.V.Bestel, S.Viaene, M.Stepanova, J.Suykens, J.Vanthienen," Benchmarking state-of-the-art classification algorithms for credit scoring," Journal of Operational Research, 2003, 54, $627-635$.

[13] T.S.Lee, I.F.Chen,"A two-stage hybrid credit scoring model using artificial neural networks and multivariate adaptive regression splines," Expert Systems with Application, 2005, 28(4), 743-752.

[14] A.Khashman,"Neural networks for credit risk evaluation: Investigation of different neural models and learning schemes," Expert Systems with Applications, 2010, 37, 6233-6239.

[15] L.C.Thomas, "A survey of credit and behavioral scoring: Forecasting financial risk of lending to consumers," International Journal of Forecasting 2002, 16, 149-172.

[16] L.Yu, SH.Wang, K.K.Lai," An intelligent-agent-based fuzzy group decision making model for financial multicriteria decision support: The case of credit scoring," European Journal of Operational Research,2009, 195, 942-959.

[17] J. L.Yang, G.H.Tzeng ,"An integrated MCDM technique combined with DEMATEL for a novel cluster-weighted with ANP method," Expert Systems with Applications, 2011, 38, 1417-1424.

[18] A.Haji, M.Assadi,"Fuzzy expert systems and challenge of new product pricing," Computers \& Industrial Engineering,2009, 56(2), 616-630. 